Journal of Teacher Education for Sustainability, vol. 21, no. 2, pp. 27-37, 2019

\title{
Detailed Images for Sustainability Development in Cross-Sectional Human Anatomy
}

\author{
Dzintra Kažoka and Māra Pilmane \\ Rìga Stradiņ̌̌ University, Riga, Latvia
}

\begin{abstract}
In medical education and preclinical, clinical and transdisciplinary studies, tutors should be able to perform and offer qualitative study courses with more articulated perspective on higher educational sustainable development in higher education. Digital images have found their direct way to education in different medical areas. The aims of the study are to assess and verify the impact of cross-sectional images on the study process of Human Anatomy. In 2018, two randomly selected groups of 200 students from $2^{\text {nd }}$ study year, Faculty of Medicine (Rìga Stradiņš University) were asked by tutors to identify several anatomical structures, using a three-dimensional virtual dissection table "Anatomage". Group I analyzed cross-sectional images after cutting and segmentation of human body with interactive tools. Group II studied X-ray pictures, computerized tomography scans and magnetic resonance images of different regions and systems. The present paper focuses on the rate of cross-sectional image effectiveness in both groups. Analyzed detailed images represent their role in teaching and learning of Human Anatomy. Interpretation of these medical images will require very deep anatomical knowledge from basic studies until clinical courses.
\end{abstract}

Key words: higher education, medical images ( $\mathrm{x}$-ray, CT and MRI), anatomical studies for more sustainable perspective

\section{Introduction}

Nowadays digitalization offers a lot of possibilities to improve the study process at higher education institutions by adopting several innovative technologies and leading to transformative experience. The quality of medical education supported by different innovations can be evaluated in various ways, quantitatively and qualitatively. The innovative solutions can widen students' and teachers' learning and teaching opportunities, provide better outcomes and contribute to the sustainability of the academic program and study courses.

Development of medical technologies changes the role of tutors and shows new trends in their daily work with students (Abdollahi, Salarvand, \& Saffar 2018; Wozniak, Ellaway, \& de Jong 2018). They must be ready to these changes and be flexible to adapt different digital images in teaching (Miles, 2005; Grignon, 2012). In anatomical practical 
classes, the usage of digital tools can be very helpful for studying different areas of the human body. Digital images not only give the possibility to students to acquire better regular materials and topics, but they can also be used as a great tool for visualization of medical information and data (Arulsamy, 2012; Jang, Oh, Choe, \& Jang 2018). With the increasing use of digital and virtual technologies in medical study courses, Human Anatomy is no exception (Johnson, Charchanti, \& Troupis 2012; Park, Chung, \& Chung 2017). In the context of education for sustainable development, this study course has been considerably changing over the past years at Rīga Stradiņš University.

An increasing number of digital technologies have been introduced to perform some practical aspects of teaching and learning the study course "Human Anatomy". Today for modern day students more and more cross-sectional images of the human body are available as materials in their studies (Arus et al., 2017; Grignon, Oldrini, \& Walter 2016b). Digital 2D images and/or 3D images, such as high resolution computerized tomography $(\mathrm{CT})$ scans and magnetic resonance $(\mathrm{MR})$, have been received with much enthusiasm and have found their way to the anatomy course and practical classes. Special attention on sectional anatomy can help medical students improve their knowledge of cross-sectional imaging (Hu, Wattchow, \& de Fontgalland, 2018).

The aims of the present study are to assess and verify the impact of cross-sectional images on the study process of Human Anatomy.

\section{Materials and Methods}

The investigation carried out in 2018 involved 200 students of the $2^{\text {nd }}$ study year at the Faculty of Medicine, Riga Stradiņš University. In practical classes, all students were asked by tutors to identify several anatomical structures, using a 3D virtual dissection table "Anatomage" (the USA). More than 100 cross-sections from 2 prepared specimens of the "Anatomage" (Table Application software from Anatomage, Inc. (Table EDU 4.0)) database were used and studied for both male and female cadavers, and over 50 clinical cases were examined from a digital library with a variety of visualization options (X-rays, CT, MRI, etc.) in different regions of the body.

Practical classes encompassing anatomical X-ray images, CT sections and MRI were provided for students. Apart from normal, regional and sectional anatomy images or radiological images, the study course also included some pathological images. Each practical class included a different set of digital images. All images were used as part of practical class topics. In some classes, a short animation was used for the presentation of current or previous materials.

Two groups were randomly created: Group I analyzed cross-sectional images after cutting and segmentation of the human body with interactive tools; Group II studied X-rays, CT scans and MRI images of different regions and systems. Similar images in all possible cross-sectional planes were displayed. The pathological findings from the cross-sectional images were used to develop several clinical questions and cases.

At the beginning of each practical class, the tutor spent about $30 \mathrm{~min}$ demonstrating the themes on the images for all students. At the end of the teaching session, understanding of the relationships between anatomical structures and the rate of cross-sectional image effectiveness was assessed in both groups by using discussion. Students analyzed several and specific anatomical structures regarding each image in a question/answer style. 
Tutors attempted to evaluate the effectiveness of learning, by asking students what type of these images contributed to their understanding of body composition and several anatomical structures. In most of the practical classes, tutors did their best to perform interdisciplinary teaching.

\section{Results}

During research and students learning observation time from researchers, students acquired the orientation of bones and organs from the lectures, practical classes and dissections. Majority of students recognized the landmarks, anatomical structures and relationships between them on cross-sectional images in three planes. Removing of different kinds of tissue offered students of both groups to learn more difficult anatomical topics and to explain details in these complicated regions.

Self-assessment exercises helped students evaluate their understanding of topographical relations and regional anatomy. In these groups, students with less prior anatomy experience were willing to focus on basics of anatomy, while students with high prior anatomy experience were willing to see and study more complex and interactive materials in cross-sectional images.

Students agreed that all these possibilities helped them better improve and understand how to study different types of information and topics in a new learning environment. Students mentioned that digital images and slices helped them conduct simulations of several procedures and provided an active study platform. In discussion sessions, students mentioned many advantages and just several disadvantages regarding the effectiveness of cross-sectional images when compared with traditional pictures from anatomy books (Table 1).

In both groups, students easily used terminology and annotated cross-sectional images. Once images were uploaded and opened, they were annotated or used without any textual explanation. Majority of these cross-sectional images included multiple annotations with text, circles and lines placed exactly where needed. Students had the option whether to use or not the annotations. For students, who were willing to selfassess their knowledge and skills, it was also possible to "hide" the annotations and terminology. Medical case scenarios or pathological cases were included by uploading the whole images.

Table 1

Some Advantages and Disadvantages of Cross-Sectional Images from Students' Discussions

\begin{tabular}{ll}
\hline \multicolumn{1}{c}{ Advantages } & \multicolumn{1}{c}{ Disadvantages } \\
\hline Ability to move, rotate, change image sizes & Costs, updates of data, cross-sectional \\
All users can view or work with the same & image sets and storage \\
image, set of images and topics & Large file sizes \\
Better memory for pictures than textual & Special knowledge and skills for reading, \\
information & interpretation and analysis of cross- \\
Collaboration between students & sectional images \\
Educational activities & Speed of some large size loading images \\
\hline
\end{tabular}


Continuation of Table 1

Large amount of medical and anatomical information

Medical and pathological cross-sectional images and cases

New and modern environment

Quality of cross-sectional images

Possibility to use zooming and dissection effects

Terminology in annotations of images

Self-study, training and simulation of procedures

Self-testing or testing of knowledge and skills

Storage of cross-sectional images

Students can learn to use the cross-sectional images

Majority of students believed that these images were good visual materials in addition to their basic studies and helpful for clinical studies. Students developed new possibilities, trained their skills and improved their knowledge to cut, move, rotate, interpret and describe the anatomical structures in the images. Some of the students were independent in the study process and reviewed individually cross-sectional images.

Three questions about the usage and effectiveness of cross-sectional images were discussed with students. The results were positive (Table 2).

Table 2

The Answers of Students about Effectiveness of Cross-Sectional Images in Both Groups

\begin{tabular}{lcc}
\hline \multicolumn{1}{c}{ Question } & \multicolumn{2}{c}{ Answer } \\
\cline { 2 - 3 } & Yes, \% & No, \% \\
\hline $\begin{array}{l}\text { Do you feel that cross-sectional images or their sets will play an } \\
\text { important role in the course "Human Anatomy" and in your future? }\end{array}$ & 90 & 10 \\
\hline $\begin{array}{l}\text { Did you obtain any new level of knowledge or skills using anatomical } \\
\text { cross-sectional images or their sets? }\end{array}$ & 75 & 15 \\
\hline $\begin{array}{l}\text { Do you recommend these cross-sectional images for current and next } \\
\text { studies of anatomy? }\end{array}$ & 95 & 5 \\
\hline
\end{tabular}

\section{Computerized Tomography and Magnetic Resonance Imaging}

In practical classes, the use of computerized tomography (CT) and magnetic resonance imaging (MRI) allowed for not only differentiation among structures, hard and soft tissue in gross anatomy, but also for the understanding of the complex pathologies and/ or pathological situations. The use of CT (Figure 1 and Figure 2) and MRI images opened new possibilities in diagnostics and/or in planning of different procedures.

Students used the information from CT and MRI (Figure 3) for the description and analysis of the findings. These images not only represented educational tools of high quality, but also offered learning, teaching and training of radiologic image interpretation of different regions of the body, such as head, neck, trunk and extremities. 


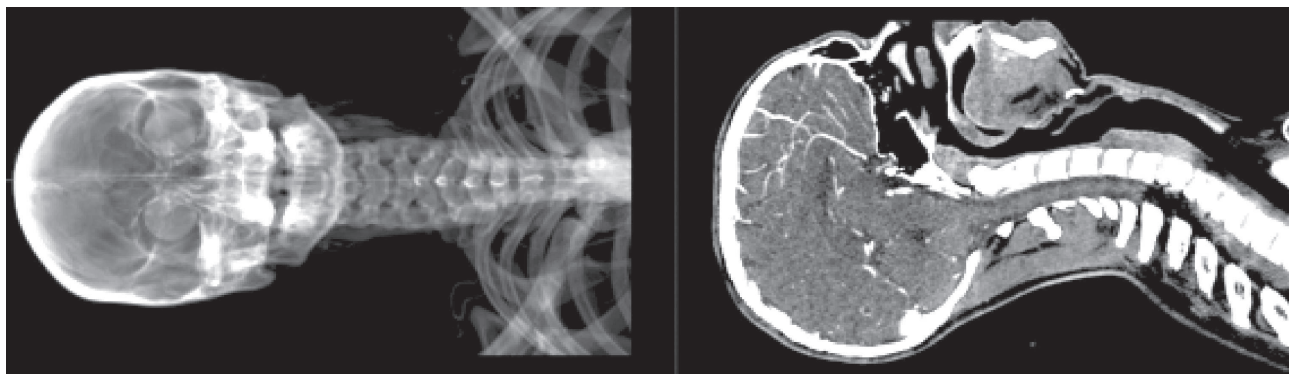

Figure 1. Digital examples of the used CT scan of the head, neck and part of the thorax

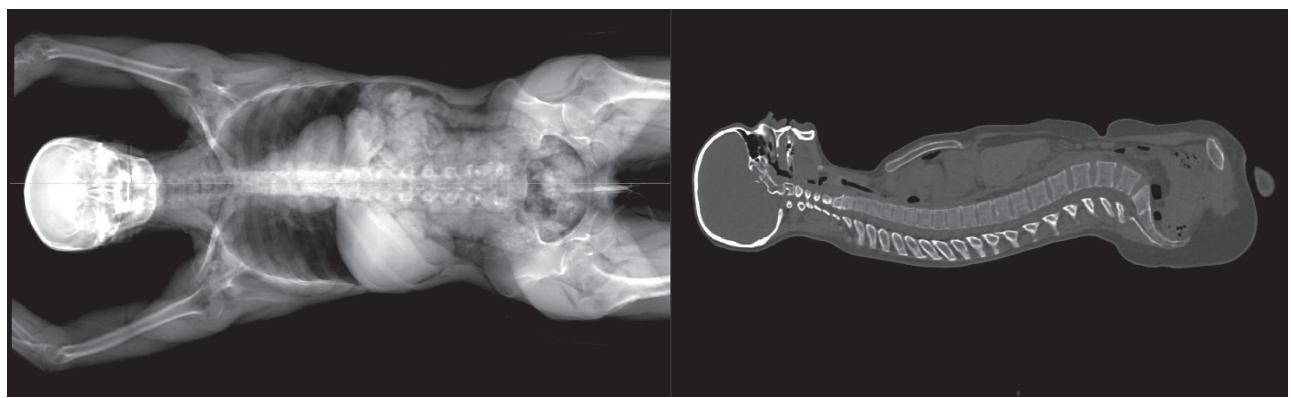

Figure 2. Digital examples of the used CT scan of some largest regions of the body
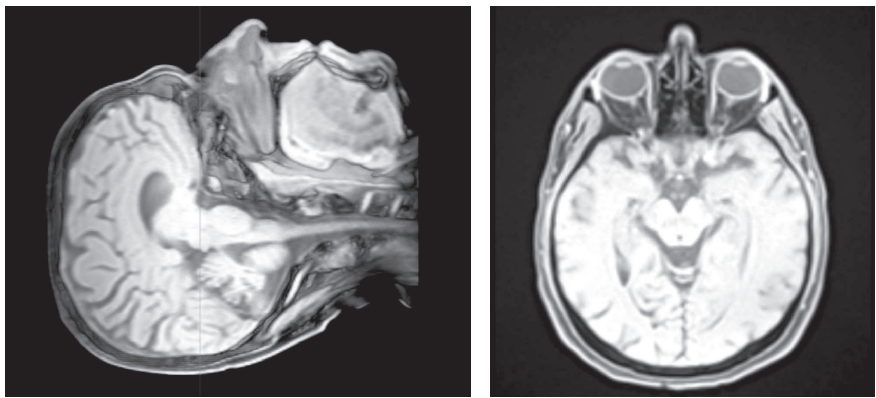

Figure 3. Digital examples of the MRI images of the head

Digital images differed in their content and quality. Majority of students preferred the cross-sectional or radiological images of a three-dimensional virtual table "Anatomage" over still images of books or any other sources used for acquiring the study course "Human Anatomy". Several students performed simulation of different procedures on the virtual body to visualize normal anatomy and examined relevant problems or pathologies using digital tools.

\section{Discussion}

The contemporary educational system includes skills and competences that are required for modern economy (Jirgensons \& Kapenieks, 2018). New technologies play a very important and powerful role in all areas of human activities (Fenesi, Mackinnon, 
Cheng, Kim, \& Wainman, 2017). It is clear that they comprise and/or transform different spheres of medicine and medical education (Starkey, 2012).

Education in cross-sectional Human Anatomy is linked with professional development of tutors and students. It is essential to periodically conduct special studies for tutors of education programs (Yoo, 2016). Some authors (Reid \& Božena, 2016) state that achieving sustainable development requires competent professionals. Perhaps, future studies and new digital experience can be next steps towards sustainable development of the basic study course "Human Anatomy" and of its content.

Students and teachers should follow the development of technologies very intensively; they should be able to use digital tools, collect and interpret different types of information and sources. Today's virtual reality can provide and open many possibilities for the study process (Sandars \& Morrison, 2007). Several existing methods can be combined and improved for the education process in different medical courses and/or disciplines. It is known that every medical study course is different and, therefore, a today's tutor should bring something new and special to the teaching and learning process (Mistry, Chetty, Gurung, \& Levell, 2019). In the teaching and learning process of the study course "Human Anatomy", new effects can be reached by the use of digital and detailed medical images.

Digital images are very powerful educational tools that effectively replace the traditional and previous standard teaching and learning methods (Foster, 2010; Norris, 2012; Chiu, Solez, \& Sergi, 2014). In Latvia we have research about action research for creating knowledge in an e-learning environment (Kapenieks \& Salite, 2012). This study has convinced us that visual tools can also be easily applied to medical students and tutors. The quality of teaching and learning processes can be detected by digital images, their usage and effectiveness. The literature review has shown that the imaging process comprises not only capturing and saving (storage) of digital images, but also their editing and sharing (Hamilton, Wang, \& McCullough, 2012). There are different types of images that can be used to acquire digital images (Kotzé, Mole, \& Greyling, 2012). In course "Human Anatomy", digital and cross-sectional images were used in a variety of different settings, including teaching and learning.

The study presented our activities and experience with digital and cross-sectional images in medical education and their inclusion into the study course "Human Anatomy". In our study course, a three-dimensional virtual table "Anatomage" was used for combination of anatomy with some other courses or disciplines. The unique capabilities of this technology are the ability to rapidly store large volumes of the images and different data that are very important and helpful for assistance in medical education, for students' activities and their assessment (Kish, Cook, \& Kis, 2013). It has become an important tool in the contemporary study process. In practical classes, the education process was much more effective because a lot of digital resources were available there. It is an excellent tool of technology that can be used for storage of 3D digital images in medicine. This digital tool involves all the topics of Human Anatomy, thus changing and supporting the education process. Students and tutors used this technology for incorporation of regional and sectional anatomy, radiology or surgery into lectures and practical classes of Human Anatomy. It allowed students at all levels to have access to Human Anatomy and virtual dissection. The possibilities of a three-dimensional virtual table "Anatomage" included not only the segmentation features, but also options for separation of each anatomical structure or system. 
From the literature analysis it is clear that virtual tools, visual slices and images can help students adapt their learning to the new study platform and technology (Chan \& Rilly, 2002; Lee, Goldman, \& Hortsch, 2018). It was recognized that virtual images can enhance the understanding of the clinical and diagnostic concepts for undergraduate students (Yammine \& Violato, 2015). These activities provided students and tutors with hands-on experience, in which our students showed and improved knowledge of Human Anatomy, regional and sectional anatomy, radiology or surgery, and at the same time learned the general principles of this virtual technology (Dettmer, Tschernig, Galanski, Pabst, \& Rieck, 2010). The ability to use all these digital images provided very important links among real anatomy, virtual anatomy and several images such as CT and MRI scans (Erkonen, Albanese, Smith, \& Pantazis, 1992; Pathiraja, Little, \& Denison, 2014). The general aim of the study was to teach medical students to understand, describe, interpret and visualize the anatomical structures of the human body using various methods and tools, ranging from classical dissection to modern imaging. One very helpful aspect of cross-sectional images was the changing possibility of their sizes and levels, directions and regions just by using fingers.

The quality of medical images plays an important role in the identification of structures not only in basic anatomy studies (Saco, Bombi, Garcia, Ramírez, \& Ordi, 2016). It is also of significance for students and medical professionals in future training and clinical procedures (Pantanomitz, Szymas, Yagi, \& Wilbur, 2012). Digital images offer many advantages and benefits. The usage of digital images in tandem with normal, regional and sectional anatomy, radiology and surgery presents one of the great opportunities for direct anatomy relationship with different medical courses and/or disciplines (Furness, 1997; Schramek et al., 2013; Custer \& Michael, 2015).

The educational applications and advantages for medical digital images are growing. Independent anatomy studies can be encouraged, supported and facilitated with the use of organs-systems-based image sets. Level of knowledge and some skills can also be assessed with these sets not only in practical classes, but also in tests, colloquiums and exams. The use and adoption of digital images in the study course "Human Anatomy" take time (Paech et al., 2017). Students must prepare for tomorrow and tutors should practice the timing of their practical classes (Fazal, Khan, \& Yunus, 2012). Digital images have been successfully used for teaching anatomy and integrated into our academic practice. Learning observations help researchers find that the current research case was open to a broader perspective for participants on more integrated learning, which was emerging as more sustainable through deeper involvement in research/studying participation. We can hypothesize that in both groups our students showed a very high level of knowledge of normal, regional and sectional anatomy in detailed cross-sectional images. Our experience and visual demonstration of digital images improved the incorporation of basic concepts into research development. As Human Anatomy and clinical medicine grow increasingly regarding the usage of digital technologies, it is ever more important that we will continue to use detailed digital images and develop new and modern directions in the anatomy study process. In the coming years, the effectiveness of digital images, short- and long-term outcomes of our study course should be tested using different hypotheses. 


\section{Conclusion and Future Research}

The study demonstrated the role of 3D virtual dissection table "Anatomage" in facilitating students' ability to interpret digital medical cross-sectional images and to understand the relationships among different anatomical structures. All used X-rays, CT scans and MRI cross-sectional images played an important role in teaching and learning of Human Anatomy. In this period, the use of cross-sectional detailed images demanded new skills and competences, created the need to repeatedly and regularly improve knowledge. Interpretation of these medical images required anatomical knowledge from basic studies to clinical courses. The incorporation of digital images and 3D visualization can range from teaching and learning anatomy to many other situations, such as development of the knowledge, skills, medical profession and research.

Our students were very motivated to improve their knowledge. Students mentioned that they were more comfortable with reading X-rays and CTs, identifying anatomical structures in different digital images, as well as training on the basis of virtual human bodies and tools for educational programs.

The chance to use the virtual technology, anatomical cross-sections and digital images of the different structures, organs and systems played an important role in the study course "Human Anatomy". The learning experience gained by $90 \%$ of students may have a potential influence on their future choice of specialty.

It should be noted that $95 \%$ of students recommended using these digital medical images for current and next studies in future.

\section{Acknowledgements}

We would like to thank all our current and previous students for their feedback on the study course "Human Anatomy".

\section{References}

Abdollahi, A., Salarvand, S., \& Saffar, H. (2018). Comparing the efficacy of virtual and conventional methods in teaching practical pathology to medical students. Iranian Journal of Pathology, 13(2), 108-112. doi: 10.30699/ijp.13.2.108

Arulsamy, S. (2012). Multimedia in medical education. Journal of Medical Sciences, $1(1), 7-11$.

Arus, N. A., Da Silva, A. M., Duarte, R., Da Silveira, P. F., Vizotto, M. B., Da Silveira, H. L. D., \& Da Silveira, H. E. D. (2017). Teaching dental students to understand the temporomandibular joint using MRI: Comparison of conventional and digital learning methods. Journal of Dental Education, 81(6), 752-758.

Chan, L., \& Rilly, K. M. (2002). Integration of digital imaging into emergency medicine education. Academic Emergency Medicine, January, 9(1), 93-95.

Chiu, B. K., Solez, K., \& Sergi, C. M. (2014). Digital pathology for e-learning and digital education - A review. Journal of Information Technology and Application in Education, 3(4), 164-168. doi: 10.14355/jitae.2014.0304.09

Custer, T., \& Michael, K. (2015). The utilization of the anatomage virtual dissection table in the education of imaging science students. Journal of Tomography \& Simulation, 1, 1-5. 
Dettmer, S., Tschernig, T., Galanski, M., Pabst, R., \& Rieck, B. (2010). Teaching surgery, radiology and anatomy together: The mix enhances motivation and comprehension. Surgial and Radiologic Anatomy, 32(8), 791-795.

Erkonen, W. E., Albanese, M. A., Smith, W. L., \& Pantazis, N. J. (1992). Effectiveness of teaching radiologic image interpretation in gross anatomy. A long-term followup. Investigative Radiology, 27, 264-266.

Fazal, Ur. R., Khan, S. N., \& Yunus, S. M. (2012). Students, perception of computer assisted teaching and learning of anatomy - in a scenario where cadavers are lacking. Biomedical Research, 23(2), 215-218.

Fenesi, B., Mackinnon, C., Cheng, L., Kim, J. A., \& Wainman, B. C. (2017). The effect of image quality, repeated study, and assessment method on anatomy learning. Anatomical Sciences Education, 10(3), 249-261. doi: 10.1002/ase.1657

Foster, K. (2010). Medical education in the digital age: Digital whole slide imaging as an e-learning tool. Journal of Pathology Informatics, 1, 14. doi: 10.4103/21533539.68331

Furness, P. N. (1997). The use of digital images in pathology. The Journal of Pathology, Nov; 183(3), 253-263. doi: 10.1002/(SICI)1096-9896(199711)183:3<253::AIDPATH927>3.0.CO;2-P

Grignon, B. (2012). Anatomy and medical imaging: A symbiotic relationship. Surgical and Radiologic Anatomy, 34(8), 673-674. doi: 10.1007/s00276-012-0998-8

Grignon, B., Oldrini, G., \& Walter, F. (2016). Teaching medical anatomy: What is the role of imaging today? Surgical and Radiologic Anatomy, 38(2), 253-260.

Hamilton, P. W., Wang, Y., \& McCullough, S. J. (2012). Virtual microscopy and digital pathology in training and education. Acta Pathologica, Microbiologica, et Immunologica Scandinavica, Apr; 120(4), 305-15. doi: 10.1111/j.1600-0463.2011.02869.x

Hu, M., Wattchow, D., \& de Fontgalland, D. (2018). From ancient to avant-garde: A review of traditional and modern multimodal approaches to surgical anatomy education. ANZ Journal of Surgery, 88(3), 2018, 146-151.

Jang, H. W., Oh, C. S., Choe, Y. H., \& Jang, D. S. (2018). Use of dynamic images in radiology education: Movies of CT and MRI in the anatomy classroom. Anatomical Sciences Education, November, 11(6), 547-553. doi: 10.1002/ase.1793

Jirgensons, M., \& Kapenieks, J. (2018). Blockchain and the future of digital learning credential assessment and management. Journal of Teacher Education for Sustainability, 20(1), 145-156. doi: 10.2478/jtes-2018-0009

Johnson, E. O., Charchanti, A. V., \& Troupis, T. G. (2012). Modernization of an anatomy class: From conceptualization to implementation. A case for integrated multimodal-multidisciplinary teaching. Anatomical Sciences Education, 5(6), 354366. doi: 10.1002/ase.1296

Kapenieks, J., \& Salite, I. (2012) Action research for creating knowledge in an e-learning environment. Journal of Teacher Education for Sustainability, 14(2), 111-130. doi: 10.2478/v10099-012-0012-x

Kish G., Cook, S.A., \& Kis, G. (2013). Computer-assisted learning in anatomy at the International Medical School in Debrecen, Hungary: A preliminary report. Anatomical Sciences Education, 6(1), 42-47.

Kotzé, S. H., Mole, C. G., \& Greyling L. M. (2012). The translucent Cadaver: An evaluation of the use of full body digital $x$-ray images and drawings in surface 
anatomy education. Anatomical Sciences Education, 5(5), 287-294. doi: 10.1002/ ase. 1277

Lee, L. M. J., Goldman, H. M., \& Hortsch, M. (2018). The virtual microscopy database sharing digital microscope images for research and education. Anatomical Sciences Education, September, 11(5), 510-515. doi: 10.1002/ase.1774

Miles, K. A. (2005). Diagnostic imaging in undergraduate medical education: An expanding role. Clinical Radiology, 60(7), 742-774.

Mistry, K., Chetty, N. C., Gurung, P., \& Levell N. J. (2019). Digital problem-based learning: An innovative and efficient method of teaching medicine. Journal of Medical Education and Curricular Development, 6, 1-5. doi: 10.1177/2382120 518825254

Norris, E. M. (2012). The constructive use of images in medical teaching: A literature review. Journal of the Royal Society of Medicine Short Reports, 3(5), 33, 1-8. doi: 10.1258/shorts.2012.011158

Paech D., Giesel F. L., Unterhinninghoten R., Schlemmer, H. P., Kuner, T., \& Doll, S. (2017). Cadaver-specific CT scans visualized at the dissection table combined with virtual dissection tables improve learning performance in general gross anatomy. European Radiology, 27(5), 2153-2160. doi: 10.1007/s00330-016-4554-5

Pantanowitz, L., Szymas, J., Yagi, Y., \& Wilbur, D. (2012). Whole slide imaging for educational purposes. Journal of Pathology Informatics, 3, 46. doi:10.4103/21533539.104908

Park, J. S., Chung, B. S., \& Chung, M. S. (2017). Digital anatomy using the surface models in portable document format file for self-learning and evaluation. Digital Medicine, 3, 133-137. doi: 10.4103/digm.digm_29_17

Pathiraja, F., Little, D., \& Denison, A. R. (2014). Are radiologists the contemporary anatomists? Clinical Radiology, 69(5), 458-461. doi: 10.1016/j.crad.2014.01.014

Reid, E., \& Božena, H. (2016). Teacher training programs for gifted education with focus on sustainability. Journal of Teacher Education for Sustainability, 18(2), 66-74. doi: 10.1515/jtes-2016-0015

Saco, A., Bombi, J. A., Garcia, A., Ramírez, J., \& Ordi, J. (2016). Current status of whole-slide imaging in education. Pathobiology, 83(23), 79-88. doi: 10.1159/ 000442391

Sandars, J., \& Morrison, C. (2007). What is the next generation? The challenge for future medical education. Medical Teacher, 29, 85-88.

Schramek, G. G., Stoevesanat, D., Reising, A., Kielstein, J. T., Hiss, M., \& Kielstein, H. (2013). Imaging in anatomy: A comparison of imaging techniques in embalmed human cadavers. BMC Medical Education, 13, 143. doi: 10.1186/1472-6920-13$143(1-7)$.

Starkey, D. (2012). Educational technology in medical imaging education. Radiographer, 59(3), 85-88.

Wozniak, H., Ellaway, R. H., \& de Jong, P. G. M. (2018). What have we learnt about using digital technologies in health professional education? Medical Journal of Australia, 209(10), 431-433. doi: 10.5694/mja18.00152

Yammine, K., \& Violato, C. (2015). A meta-analysis of the educational effectiveness of three-dimensional visualization technologies in teaching anatomy. Anatomical Sciences Education, 8, 525-538. 
Yoo, J. H. (2016). The effect of professional development on teacher efficacy and teachers self-analysis of their efficacy change. Journal of Teacher Education for Sustainability, 18(1), 84-94. doi: 10.1515/jtes-2016-0007

Correspondence concerning this paper should be addressed to Dzintra Kažoka, Associate Professor, Institute of Anatomy and Anthropology, Rỉga Stradiņš University, Kronvalda boulevard 9, Riga, LV-1010, Latvia. Email: Dzintra.Kazoka@rsu.lv 